\title{
Influence of boundary conditions on the prediction of springback and wrinkling in sheet metal forming
}

\author{
D.M. Neto ${ }^{a, *}$, M.C. Oliveira ${ }^{a}$, A.D. Santos ${ }^{b}$, J.L. Alves $^{c}$, L.F. Menezes ${ }^{a}$ \\ a CEMUC, Department of Mechanical Engineering, University of Coimbra, Polo II, Rua Luís Reis Santos, Pinhal de Marrocos, 3030-788 Coimbra, Portugal \\ b INEGI/FEUP, Faculty of Engineering, University of Porto, Rua Dr. Roberto Frias, 4200-465 Porto, Portugal \\ c CMEMS, Microelectromechanical Systems Research Unit, University of Minho, Campus de Azurém, 4800-058 Guimaraes, Portugal
}

\section{A R T I C L E I N F O}

\section{Keywords:}

Sheet metal forming

Wrinkling

Finite element analysis

Boundary conditions

DD3IMP

\begin{abstract}
A B S T R A C T
The high-strength steel sheets currently used in the automotive industry are prone to non-traditional behaviour during forming, being wrinkling and springback two of the most challenging geometrical predictions for numerical simulation. Thus, the finite element method requires accurate and reliable numerical models. This study presents the experimental and numerical analysis of a rail component with high tendency to develop wrinkling and 2D springback. Two different materials are used for the sheet blank, namely a mild steel (DC06) and a dual phase steel (DP600). The frictional behaviour between each metallic sheet and the forming tools is evaluated through the flat-die test, allowing the determination of a friction coefficient as a function of the normal pressure. The influence of the applied boundary conditions on the numerical results is evaluated by means of two distinct numerical models (full blank geometry and 1/4 of the blank with symmetry conditions). The results show that the wrinkling behaviour is strongly affected by the blank's material, as well as by the symmetry conditions defined in the numerical model. In fact, considering the full model of the blank, the numerical results are in better agreement with the experimental ones. However, the computational cost of the numerical simulation considering the full blank is substantially higher than using $1 / 4$ of the blank.
\end{abstract}

\section{Introduction}

In order to reduce the fuel consumption of automobiles, the use of lightweight materials, such as advanced high-strength steels (AHSS), has been progressively adopted in the automotive industry [1]. However, these materials present low formability, resulting from the higher values of yield stress and lower elongation compared to conventional steels. Furthermore, the AHSS are more susceptible to non-traditional behaviour, among which springback, wrinkling and fracture (or necking) are the main failure modes in sheet metal forming [2].

Since the dimensional accuracy of formed products is strongly deteriorated by the springback during unloading [3], the larger and more unpredictable springback observed in AHSS requires more time for the trial-and-error die design in order to compensate it [4]. Therefore, several techniques have been proposed to suppress or compensate springback, all of them aiming to reduce the bending moment that is its driving force [5,6]. A new technique was recently proposed by Komgrit et al. [7] to eliminate U-bending springback, where the bottom is additionally bent with a counter punch, generating a negative bending moment. They concluded that an appropriate combination of the sheet clamping force and bottom pushing-up force allows eliminating the springback without generating any geometrical imperfections at the bottom part. Also, an important geometrical defect occurring in the sheet metal forming process is the wrinkling, which is a local buckling generated by excessive compressive stresses [8]. It can be categorized in two main types: flange wrinkling and wall wrinkling. Although both are initiated from the compressive hoop stresses, the formation of wall wrinkling is easier to develop than the wrinkling on the flange, because the sheet is unsupported by the tool [9]. On the other hand, the suppression of wall wrinkles by control of the blank holder force [10] is more difficult than the suppression of flange wrinkles.

Nowadays, the prediction of such forming defects using numerical simulation is extremely important and a "almost mandatory" practice in modern industry, thus allowing reduction of traditional costly trial-anderror experiments. However, both the accuracy and the reliability of the finite element results are strongly dependent on the numerical algorithms adopted (temporal integration, finite element formulation, constitutive material model, treatment of contact constraints, etc.), as

\footnotetext{
* Corresponding author.

E-mail addresses: diogo.neto@dem.uc.pt (D.M. Neto), marta.oliveira@dem.uc.pt (M.C. Oliveira), abel@fe.up.pt (A.D. Santos), jlalves@dem.uminho.pt (J.L. Alves), luis.menezes@dem.uc.pt (L.F. Menezes).
} 
reported by Tekkaya and Martins [11]. Despite the large importance of the wrinkling prevention in sheet metal forming, there are relatively scarce attempts on the improvement of its prediction [12]. In fact, the accurate prediction of wrinkling still represents a challenge for the numerical simulation. This results from the fact that the wrinkles are affected by many factors, such as the stress state, the mechanical properties of the material, the geometry of the tools and the boundary conditions [13]. The influence of planar anisotropy on the occurrence of wrinkling was analysed by De Magalhães Correia and Ferron [14] using the bifurcation analysis [15] and the finite element simulation. The example analysed was the deep drawing of a conical cup and the wrinkle wavelengths predicted with the bifurcation analysis were in good agreement with the finite element results, as long as the anisotropic behaviour of the material is well described. The influence of the tool geometry on the sidewall wrinkling was investigated by Neto et al. [16] in a cylindrical cup drawing and they concluded that the amplitude of the wrinkle waves, developed along the unsupported sidewall region of the cup, is strongly affected by the height of the dome present in the punch geometry. The application of symmetry conditions in finite element models allows a significant reduction on the number of degrees of freedom, while improves the numerical stability. Nevertheless, the applied boundary conditions are sometimes violated due to the material model (anisotropy), the applied loading or any instability [11], thus creating errors in the numerical solution.

The purpose of the current study is to assess the influence of the boundary conditions applied in the model on the wrinkling prediction. Hence, the presented approach provides new insights into the causes affecting the wrinkling behaviour in sheet metal forming processes. Thus, a rail component is selected with high tendency to develop both wrinkling and springback, being the analysis performed both experimentally and numerically. In order to take into account the effect of the blank material on the wrinkling behaviour, two distinct steel sheets are considered, namely the DC06 mild steel and the DP600 dual phase steel. The full geometry of the blank is adopted in the numerical model, which is compared with the classical model composed by $1 / 4$ of the blank (considering symmetry conditions). The organization of the paper considers the following sections. The experimental setup of the forming process is described in Section 2, including the procedure used to evaluate the friction coefficient as a function of the normal contact pressure. The proposed finite element models are presented in Section 3 , which considers different boundary conditions for the blank and an advanced friction model for the contact behaviour between the blank and the tools. The comparison between experimental and numerical results is presented in Section 4, highlighting the influence of the blank's material and the finite element model adopted. The main conclusions of this study are outlined in Section 5.

\section{Experimental procedure}

This study deals with the sheet metal forming of a rail geometry (Fig. 1), prone to 2D springback behaviour and wrinkling on the top surface. This component has been defined as a benchmark under the

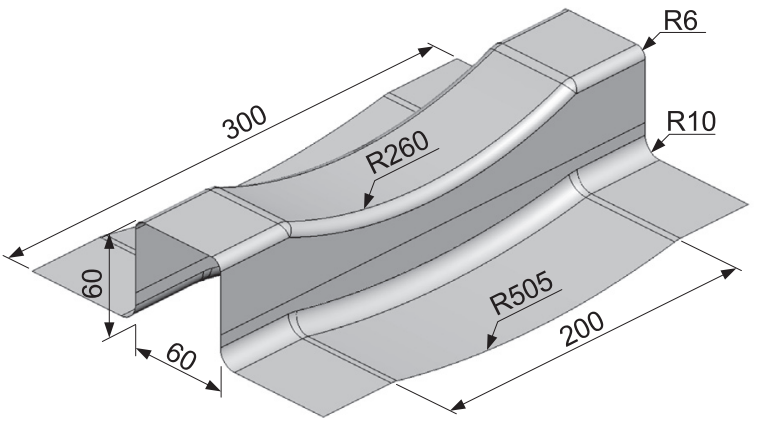

Fig. 1. Target geometry of the rail, including the main dimension (in millimetres).

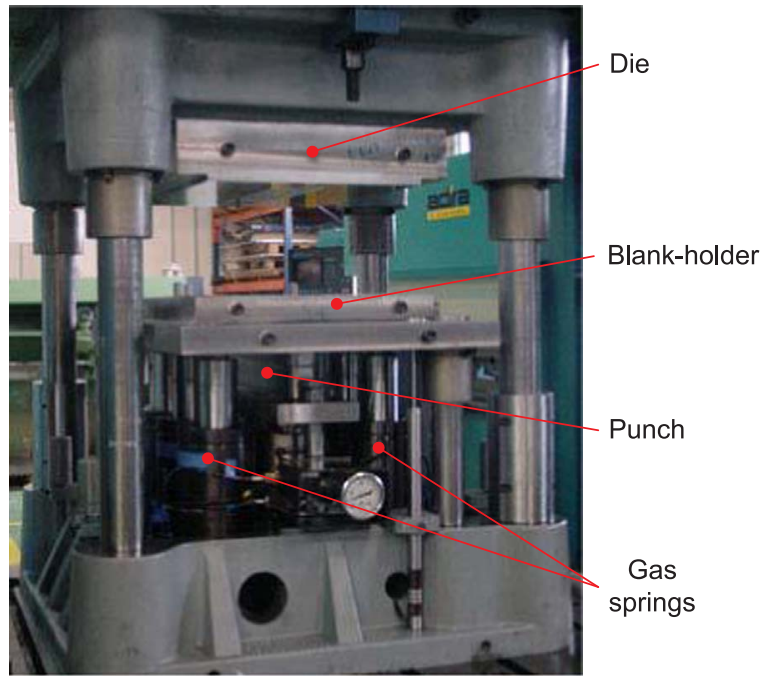

Fig. 2. Experimental tool basis used to perform the forming process.

international project 3DS - Digital Die Design System [17], which aimed at improving the ability of finite element codes to predict forming defects, specifically the final geometry of sheet metal forming parts. The validation of the developed numerical models required a representative set of experimental results. Therefore, special care was devoted to the standardization of the experimental procedure, namely the cutting of blanks from sheets, the lubrication method, the ram speed and the coordinate system for the measurements of the formed parts [18].

\subsection{Forming process}

The experimental setup of the sheet metal forming operation comprises four active tools (punch, die, blank-holder and counterpad), which are attached to a common basis, as shown in Fig. 2. The forming process is divided in three phases. In the first one, the die moves downward, clamping the blank between the die and the blankholder with an initial prescribed force of $90 \mathrm{kN}$. This blank-holder force is obtained by six nitrogen gas springs (see Fig. 2), being all connected, in order to assure the same pressure in each of them. In the second phase, the die and the blank-holder move together downward, forming the part and defining a punch penetration of $60 \mathrm{~mm}$. During this stage the gas springs are being compressed, thus increasing the blank-holder force from 90 to $130 \mathrm{kN}$. The third phase is the part removal from tools, in which the springback or elastic recovery takes place.

The blank is a square with $300 \mathrm{~mm}$ length sheared from $1500 \times 1600 \mathrm{~mm}$ rectangular rolled sheets (mild steel DC06 and dual phase DP600) with $1.0 \mathrm{~mm}$ thickness. The forming operations are carried out with the rolling direction of the blank sheet aligned with the longitudinal direction of the rail. In order to guarantee a correct amount of lubricant and its uniform distribution in the blank, the lubrication method suggested by Santos et al. [18] was adopted. The amount of lubricant (Quaker 6130) is defined as $1.4 \mathrm{~g} / \mathrm{m}^{2} /$ face. The evolution of both the punch and the blank-holder force was recorded by a data acquisition system, from load cells placed under each gas spring and under the punch. The press ram speed was $20 \mathrm{~mm} / \mathrm{s}$, while the die vertical displacement is experimentally evaluated through a displacement transducer. At least five forming tests were performed in order to check the reproducibility of the experiments. The wrinkling defect on the top surface of the rail is shown in Fig. 3 for two distinct steels, highlighting the strong influence of the material on the wrinkle shape geometry. 


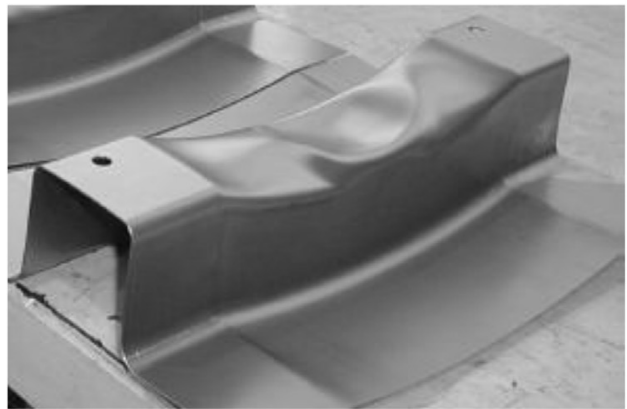

(a)

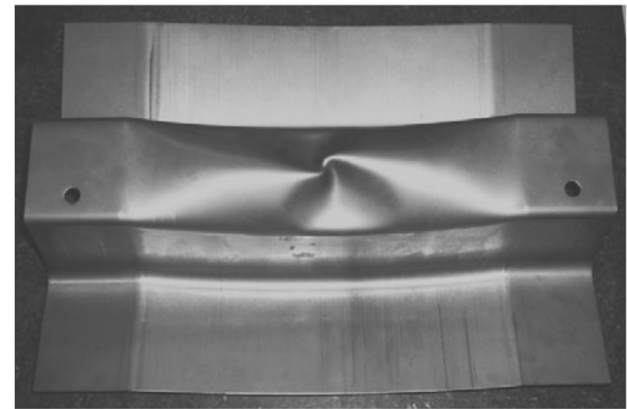

(b)

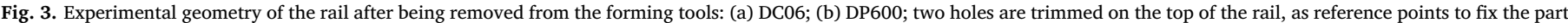
during measurement.

\subsection{Part measurements}

Wrinkling and springback are two fundamental geometrical behaviours arising in parts obtained by sheet metal forming processes. This kind of defects can be easily examined by visual inspection. Nevertheless, a quantitative evaluation of these forming defects by means of geometrical measurements is essential, allowing a meaningful comparison between experimental and numerical results. Optical scanning systems can be used for the evaluation of both global defects (twisting and springback) and local defects (wrinkles) [19,20]. However, the accuracy of the non-contact measurement inspection techniques is substantially lower than the one of the contact measurement systems (e.g. coordinate measuring machines) [21]. Thus, in the present study four section profiles of the rail are measured, after springback, using a conventional metrology equipment, i.e. the 3D coordinate measuring machine (DEA Gramma Record) presented in Fig. 4(a). Two holes are punched on the top surface of the rail (see Fig. 3), which are used to position and fix the rail in a jig for measurement (see Fig. 4(a)). Besides, the reference coordinate system is coincident with one of the holes, as shown in Fig. 4(b). The study performed by Santos et al. [22] shows that such piercing operation has a very small influence in the final geometry of the rail, recommending its exclusion from the numerical model.

The four section profiles selected for measurement (outside peel of the rail) are defined in Fig. 4(b), namely two sections in the longitudinal direction (L1 and L2) and two sections in the transverse direction (A and $\mathrm{B}$ ). The number of points evaluated in each section profile was selected in order to obtain $3 \mathrm{~mm}$ of distance between consecutive points. This leads to 75 points in each section of the longitudinal direction and 100 points in each section of the transverse direction. Five sets of measurements are performed for each section profile in order to check the reproducibility of the experimental data.

\subsection{Friction tests}

The most common method to determine the friction coefficient used in the numerical simulation of forming processes is its calibration according to the experimental values of the punch force [23]. Nevertheless, in the present study, the friction conditions between the blank (lubricated) and the forming tools were experimentally evaluated using the flat-die test, which is often employed to determine the coefficient of friction [24]. In this test, the sheet specimen $(600 \mathrm{~mm}$ of length and $50 \mathrm{~mm}$ of width) cut along the rolling direction is compressed between two flat dies and then pulled in the horizontal direction, as illustrated in Fig. 5(a). The flat dies were produced using the same steel of the forming tools, i.e. the classical tool steel (no heat treatment, hardness around 45 HRC). Fig. 5(b) presents the two flat dies, highlighting the contact area of each one with the dimension of $10 \times 10 \mathrm{~mm}$.

During the flat-die test, the sliding speed is kept constant and equal to $1.5 \mathrm{~m} / \mathrm{min}$, which is approximately equal to the press ram speed. The normal load applied on the flat dies increases during the test, allowing to reproduce the pressure level obtained under the blank-holder during the forming stage. This approach allows to evaluate the evolution of the friction coefficient with the normal pressure [25]. Both the pulling (friction) force and the local holding forces are accurately measured by load cells. Nevertheless, a special care is required to obtain a perfect parallelism between the two flat dies. In fact, the misalignment (convergence or divergence) between the flat dies can lead to wrong values of friction coefficient. In order to check the reproducibility, each

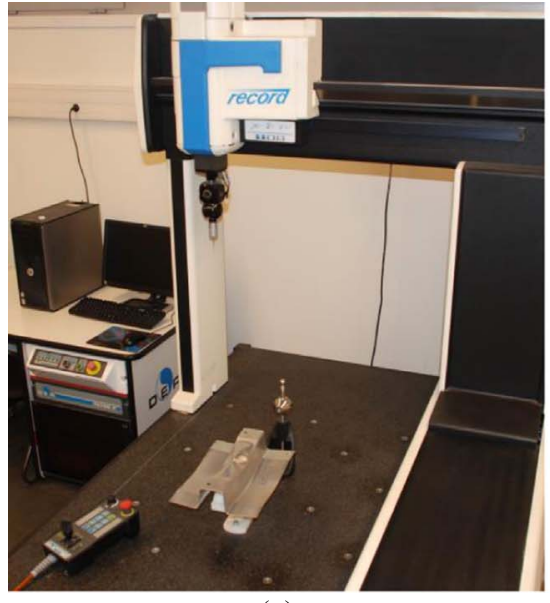

(a)

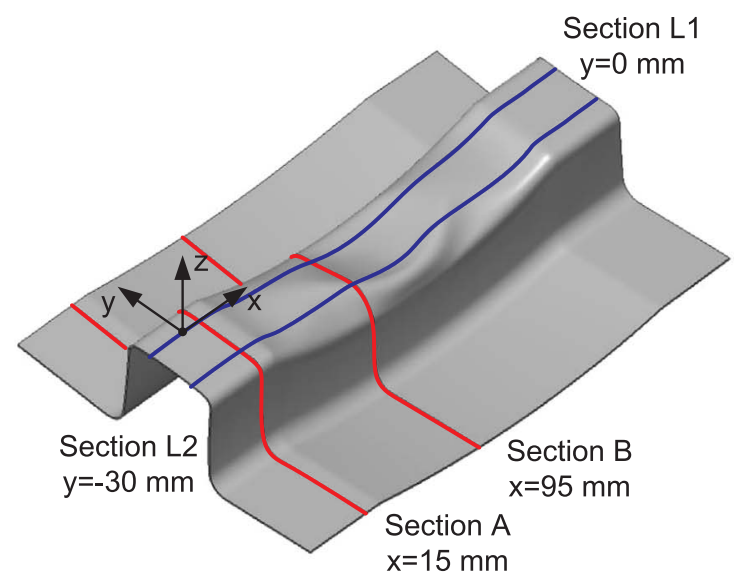

(b)

Fig. 4. Measurements of the obtained rail: (a) 3D coordinate measuring machine; (b) definition of the four section profiles and reference coordinate system. 


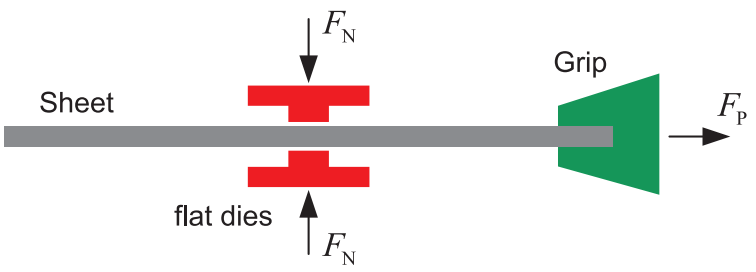

(a)

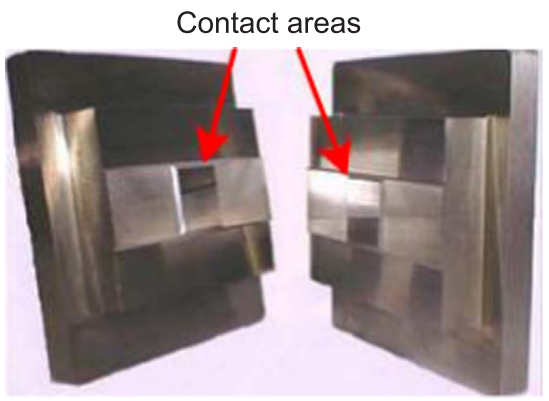

(b)

Fig. 5. Flat-die test used to evaluate the friction behaviour of both steel sheets: (a) scheme of the flat-die test set-up; (b) experimental flat dies produced with the same steel of the forming tools [25].

test is performed at least twice. Before each test, tools and sheet samples are strictly cleaned and then lubricated with a homogeneous layer of lubricant (Quaker 6130 using $1.4 \mathrm{~g} / \mathrm{m}^{2} /$ face). During the test, both the pulling force and normal force are monitored, allowing to assess the evolution the friction coefficient according to the Coulomb's law, given by:

$\mu=\frac{F_{\mathrm{P}}}{2 F_{\mathrm{N}}}$,

where $F_{\mathrm{P}}$ and $F_{\mathrm{N}}$ denote the pulling and normal forces, respectively.

\section{Numerical model}

The numerical simulations were carried out with the in-house static implicit finite element code DD3IMP [26], which has been specifically developed to simulate sheet metal forming processes [27]. The evolution of the deformation process is described by an updated Lagrangian scheme. In each increment, an explicit approach is used to calculate a trial solution for the configuration, which is iteratively corrected using a fully implicit Newton-Raphson scheme. The frictional contact problem is regularized by the augmented Lagrangian method, leading to a non-linear system of equations involving both displacements and contact forces. The abovementioned Newton-Raphson scheme is used to solve the non-linearities associated with the elastoplastic behaviour of the deformable body and the contact problem, using a single loop. In order to improve the computational performance, some high performance computing techniques have been incorporated to take advantage of multi-core processors [28]. All numerical simulations were performed on a computer machine equipped with an Intel $^{\circledR}$ Core $^{\mathrm{TM}}$ i7$4770 \mathrm{~K}$ Quad-Core processor $(3.5 \mathrm{GHz})$ and the Windows 8.1 Pro (64bit platform) operating system.

\subsection{Materials}

The mechanical behaviour of both steel sheets (DC06 and DP600) is assumed elastoplastic, considering isotropic elastic behaviour and anisotropic plastic behaviour. The elastic behaviour is described by the Hooke's law with Young's modulus of $210 \mathrm{GPa}$ and Poisson ratio of 0.30 , for both steels [2]. Nevertheless, it should be mentioned that recent studies, performed on a wide range of alloys, indicate that there is no linear elastic region in the stress-strain behaviour [29,30]. In this context, Chen et al. [30] proposed a "Universal Law" to describe the elastic behaviour taking into account the strain, which depends only on the material strength and the Young's modulus. Regarding the plastic behaviour, the isotropic hardening is described by the Swift law:

$Y=K\left(\varepsilon_{0}+\bar{\varepsilon}^{\mathrm{p}}\right)^{n} \quad$ with $\quad \varepsilon_{0}=\left(\frac{Y_{0}}{K}\right)^{1 / n}$,

where $K, \varepsilon_{0}$ and $n$ are the material parameters, while $\bar{\varepsilon}^{\mathrm{p}}$ denotes the equivalent plastic strain and $Y_{0}$ denotes the initial value of the yield stress. The kinematic part of the work hardening is described by the non-linear law with saturation proposed by Frederick and Armstrong [31], given by:

$\dot{\mathbf{X}}=C_{\mathrm{X}}\left[\frac{X_{\text {sat }}}{\bar{\sigma}}\left(\boldsymbol{\sigma}^{\prime}-\mathbf{X}\right)-\mathbf{X}\right] \dot{\bar{\varepsilon}}^{\mathrm{p}} \quad$ with $\quad \mathbf{X}(0)=\mathbf{0}$,

where $X_{\text {sat }}$ characterizes the saturation value of the back-stress tensor $\mathbf{X}$, while the material parameter $C_{\mathrm{X}}$ characterizes the rate of approaching the saturation. The inclusion of the kinematic hardening improves the springback prediction in the sheet metal forming simulation [32], particularly in high strength steels [33,34], for which the springback effect is stronger. The five material parameters involved in the hardening laws are identified using the following experimental tests: (i) uniaxial tensile test up to localized necking; (ii) monotonic simple shear test up to $50 \%$ amount of shear and (iii) Bauschinger simple shear test after $20 \%$ amount of monotonic shear [35]. The stress-strain curve obtained for each experimental test, performed for specimens aligned with the rolling direction, is presented in Fig. 6 for each material under analysis (DC06 and DP600).

The procedure used to identify the best set of constitutive parameters is based on the minimization of the difference between the predicted and the experimental values [36]. The obtained material parameters for the isotropic hardening described by the Swift law and the non-linear kinematic hardening defined by the Frederick-Armstrong law are listed in Table 1 for each material. The adopted constitutive model allows to describe accurately the mechanical behaviour of both steels, as shown in Fig. 6, highlighting the large difference in terms of hardening behaviour, between the mild steel (DC06) and the high strength steel (DP600). In fact, the Bauschinger effect (reduction of the yield stress under reverse loading) is more evident in the high strength steel than in the mild steel, which is in agreement with the results presented by Chen et al. [32].

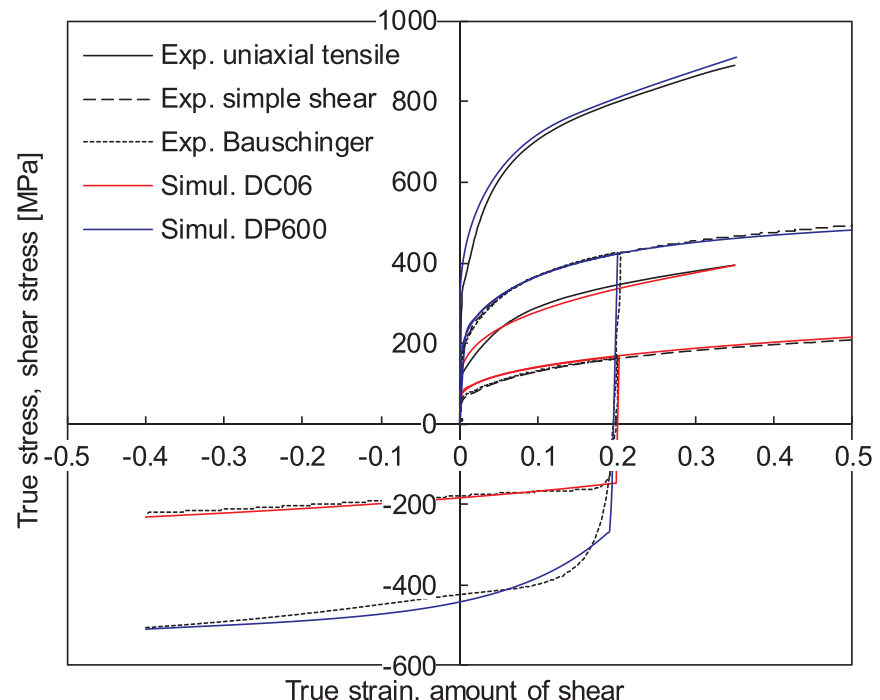

Fig. 6. Comparison between experimental and numerical stress-strain curves obtained from uniaxial tensile test, simple shear and Bauschinger simple shear after $20 \%$ forward shearing. The hardening behaviour is described by the Swift law (isotropic hardening) and the Armstrong and Frederick law (kinematic hardening). 
Table 1

Parameters of both isotropic and kinematic hardening law for each material.

\begin{tabular}{llllll}
\hline Material & $Y_{0}[\mathrm{MPa}]$ & $K[\mathrm{MPa}]$ & $n$ & $C_{\mathrm{X}}$ & $X_{\text {sat }}[\mathrm{MPa}]$ \\
\hline DC06 & 122.2 & 435.0 & 0.219 & 1.45 & 116.7 \\
DP600 & 308.3 & 790.2 & 0.132 & 15.8 & 169.2 \\
\hline
\end{tabular}

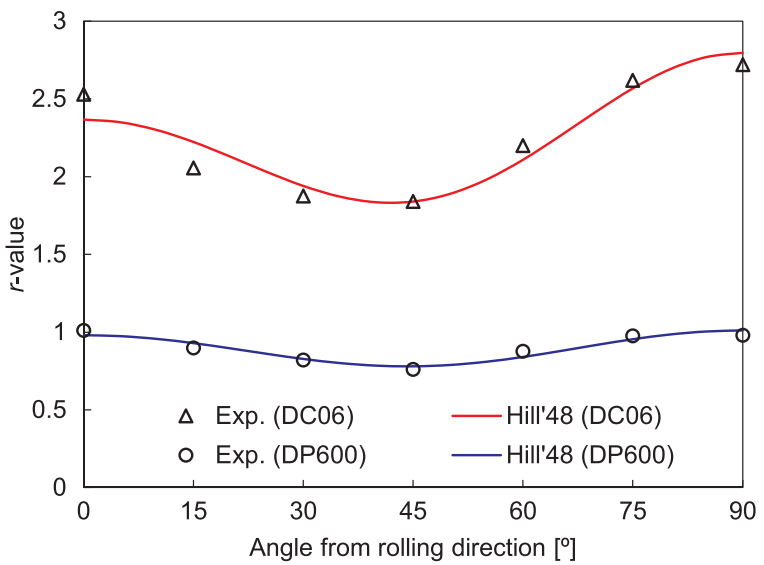

Fig. 7. Evolution of the coefficient of anisotropy ( $r$-value) in the plane of the sheet metal for each material. Comparison between experimental results and Hill'48 yield criterion.

Table 2

Anisotropy parameters of the Hill'48 yield criterion for each material.

\begin{tabular}{lllllll}
\hline Material & $F$ & $G$ & $H$ & $L$ & $M$ & $N$ \\
\hline DC06 & 0.251 & 0.297 & 0.703 & 1.500 & 1.500 & 1.283 \\
DP600 & 0.490 & 0.505 & 0.495 & 1.500 & 1.500 & 1.273
\end{tabular}

The orthotropic plastic behaviour of both metallic sheets is described in the present study by the classical Hill'48 yield criterion, which is commonly used for steels [37]. The anisotropy parameters of the Hill'48 yield criterion are determined from the experimental $r$ values, evaluated using uniaxial tensile tests performed at different orientations with respect to the rolling direction, namely $0^{\circ}, 15^{\circ}, 30^{\circ}$, $45^{\circ}, 60^{\circ}, 75^{\circ}$ and $90^{\circ}$. In order to check the reproducibility, each experimental test is performed at least twice. All tensile tests were conducted at the constant strain rate of $\dot{\varepsilon}_{0}=10^{-3} \mathrm{~s}^{-1}$ [35]. The $r$-values determined experimentally as a function of the tensile direction (angle from rolling direction) are presented in Fig. 7 for each material. The mild steel DC06 exhibits a strong variation in the coefficient of anisotropy, while the dual phase steel DP600 is almost isotropic in the rolling plane, which is in agreement with the results of Chalal et al. [38]. For each material analysed, the four coefficients $F, G, H$ and $N$ of the Hill'48 yield criterion are identified by the least squares fitting using the seven experimental $r$-values. The obtained values are presented in Table 2. The sheet is assumed isotropic through the thickness, leading to $L=M=1.5$. Since the identification of the hardening law parameters was carried out using specimens oriented along the rolling direction, the relation $G+H=1$ is added. This imposes the equality between the yield stress along the rolling direction and the equivalent stress given by Hill'48 criterion for the same direction. For both materials, the evolution of the coefficient of anisotropy in the plane of the sheet metal, predicted by the Hill'48 yield criterion, is in good agreement with the experimental values, as shown in Fig. 7.

\subsection{Friction model}

The value of the friction coefficient used in all numerical simulations of the present study is dependent on the local contact pressure. For both materials analysed, the friction behaviour between the blank and

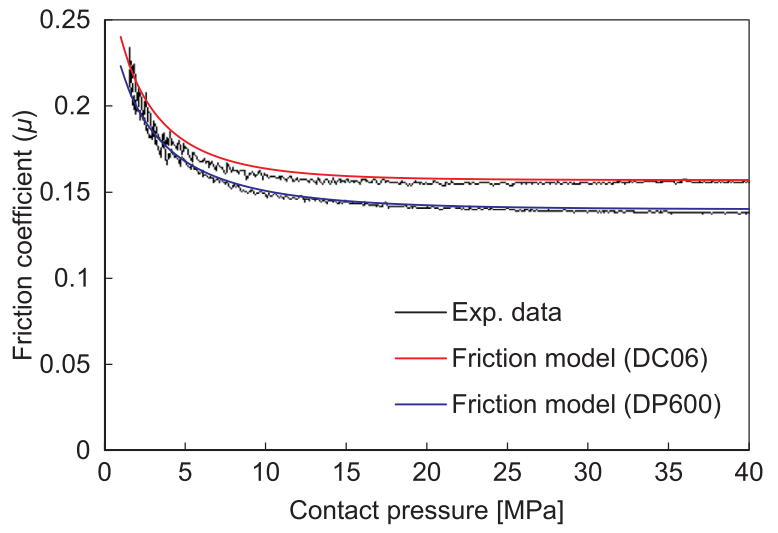

Fig. 8. Evolution of the friction coefficient with the normal contact pressure. Comparison between experimental data and the adopted friction model.

the forming tools was experimentally evaluated using flat-die tests (see Section 2.3). Thus, the advanced friction model proposed by Wouters et al. [25] is adopted in the present study, where the Coulomb's friction coefficient is defined by a Hockett-Sherby law:

$\mu=B-(B-A) \exp \left(-m P^{n}\right)$,

where $A, B, m$ and $n$ are numerical fitting parameters, while $P$ denotes the normal contact pressure.

For each material of the blank, the four parameters of the friction model are identified using the experimental results from the flat-die tests [25]. Fig. 8 presents the experimental evolution of the friction coefficient value with the normal contact pressure. For both sheet steels (DC06 and DP600), the value of the friction coefficient decreases with the increase of the contact pressure, achieving a saturation level for large pressure values ( $>10 \mathrm{MPa})$. This can be explained by the influence of the lubricant during the contact. Since the oil is located in the valleys of the roughness of the contacting surfaces, the lubricated area between the sheet and the tool increases with increasing contact pressure. The reduction of the friction coefficient with the contact pressure rise was confirmed also by the "step" test, where the normal pressure is kept constant (three different levels). This test allows obtaining the friction coefficient for three different values of contact pressure, using a sliding distance of $50 \mathrm{~mm}$ for each pressure value [25]. The obtained friction coefficient values are identical to the ones presented in Fig. 8, where the applied contact pressure increases linearly with the prescribed displacement (see Fig. 5(a)). Globally, the friction coefficient of the DP600 is lower than the one obtained for the DC06 (see Fig. 8), which is in agreement with the results presented by Kersting et al. [39] using the ring compression test.

The identification of the parameters involved in the friction model was carried out by fitting the numerical model to experimental data from the flat-die tests. The obtained values for the parameters are listed in Table 3 for each material. The adopted friction model is able to reproduce closely the frictional behaviour of both materials, as shown in Fig. 8. The measured friction coefficient is quite high for both materials, ranging approximately between 0.25 and 0.15 .

\subsection{Boundary conditions}

Typically, the finite element model takes advantage of the existing

Table 3

Parameters of the adopted friction model for each material.

\begin{tabular}{lllll}
\hline Material & $A$ & $B$ & $m$ & $n$ \\
\hline DC06 & 0.31 & 0.16 & 0.61 & 0.71 \\
DP600 & 0.29 & 0.14 & 0.59 & 0.65 \\
\hline
\end{tabular}


symmetry conditions in order to reduce the computational cost of the numerical analysis. In the present study, the forming tools present two symmetry planes, allowing to model only one quarter of the blank, which also presents material symmetry. Nevertheless, the wrinkles arising on the top surface of the rail are located close to the symmetry planes, as shown in Fig. 3. Therefore, this study intends to evaluate the influence of the adopted boundary conditions on the wrinkling prediction. Hence, the full geometry of both the blank and forming tools is modelled, which is compared with the numerical model composed by $1 / 4$ of the blank (considering symmetry conditions).

Since the wrinkling phenomena is a result from instability, the numerical model that considers the full blank geometry is numerically perturbed. Accordingly, the proposed finite element model presents a small rotation of the blank $\left(1^{\circ}\right)$, relative to the forming tools. Indeed, both the blank geometry and its rolling direction are rotated equally, inducing non-symmetrical conditions on the forming process [11]. Furthermore, the blank-holder force is equally divided among the two flanges of the rail to better approximate the experimental conditions. Thus, the gap between the die and the blank-holder is not mandatorily the same in both flanges of the rail, which is adjusted in each increment in order to guarantee a linear increase of the blank-holder force for each flange.

\subsection{Sheet and tools discretization}

The blank is discretized with hexahedral finite elements associated with a selective reduced integration technique [40]. The accurate prediction of the wrinkling phenomenon in the sheet metal forming simulation requires a fine mesh, able to reproduce sharp curvatures [16]. Thus, a regular finite element mesh is adopted in the Oxy plane (element size of $1.0 \mathrm{~mm}$ in the central region), as shown in Fig. 9, using two layers of finite elements through the thickness. The turning angle for each finite element in contact with the die radius $(5 \mathrm{~mm})$ is about $5.7^{\circ}$, which is the maximum value recommended by Li et al. [41] for an accurate springback prediction. The modelling of the full blank comprises 130,000 finite elements, while $1 / 4$ of the blank requires only 32,500 finite elements (see Fig. 9).

In the present study, the geometry of the forming tools (rigid) is modelled by Nagata patches [42], allowing an accurate description of the geometry using a small amount of patches [43]. The nodal normal vectors required for the contact surface smoothing approach are

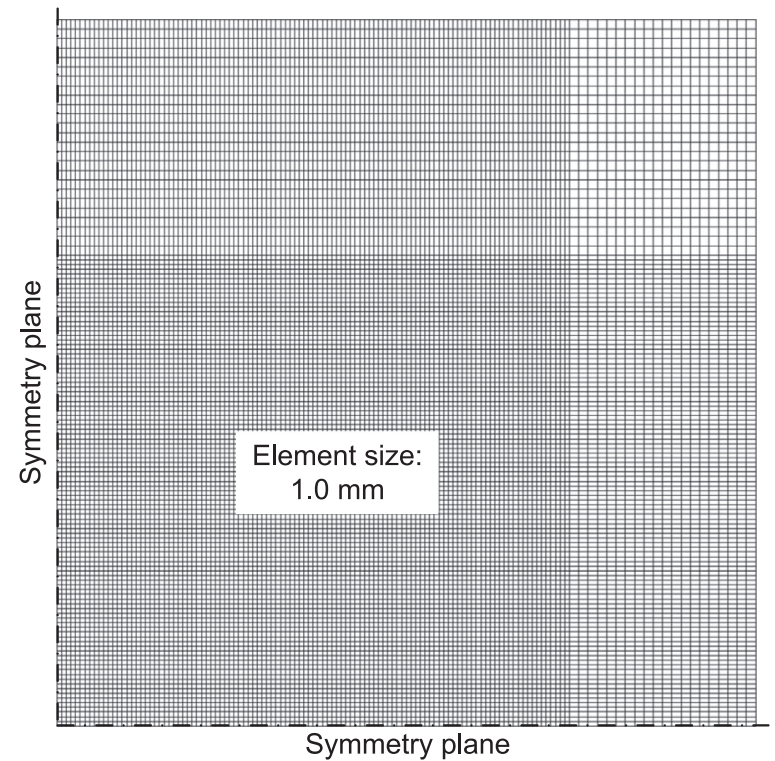

Fig. 9. Discretization of the blank (1/4) using 32,500 hexahedral finite elements (2 layers through the thickness).

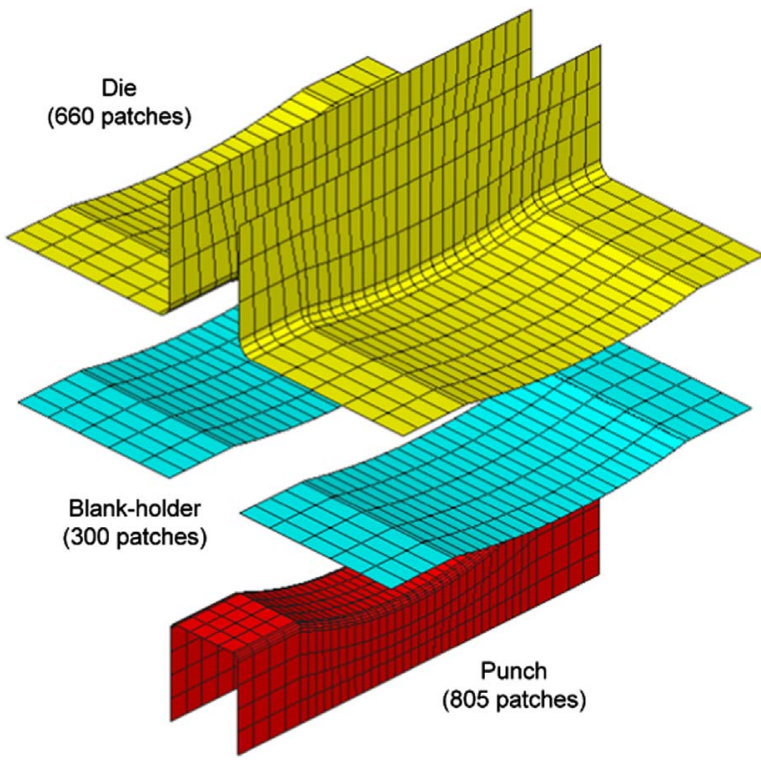

Fig. 10. Discretization of the forming tools using Nagata patches.

evaluated through the IGES file [44]. The discretization of the three tools involved in the numerical simulation is presented in Fig. 10. The surface of the punch is described by 660 patches, the blank-holder comprises 300 patches and the surface of the die is discretized with 805 patches. Since the number of patches defining the tools is insignificant in the total computational time, the model presented in Fig. 10 is used in both finite element models (1/4 and full blank).

\section{Results and discussion}

The comparison between numerical and experimental results is presented in this section, namely the punch force evolution and the final geometry of the rail. Regarding the later, the springback of the flange and the wrinkles on the top of the rail are the forming defects evaluated in the present study. Besides, the two finite element models are compared both in terms of accuracy and computational cost.

\subsection{Forming forces}

The comparison between numerical and experimental punch force evolution is presented in Fig. 11, for each material used in this study (DC06 and DP600). The blank-holder force is imposed in the numerical model according to the defined experimental evolution, i.e. linear increase with the punch displacement. Considering the same material for the blank, both finite element models ( $1 / 4$ and full blank) provide identical predictions for the punch force evolution. Nevertheless, the experimental value of the force is slightly overestimated by the numerical model, as shown in Fig. 11. Regarding the mild steel DC06, the initial slope of the numerical punch force evolution is higher than the experimental one, as shown in Fig. 11 (a). Consequently, the instant for which the wrinkle arises (drop in the punch force) occurs earlier. For both materials, the occurrence of wrinkling development on the top surface of the rail induces a drop in the punch force, which is more evident in the numerical simulation (see Fig. 11). Besides, the decrease of the force for the mild steel DC06, which occurs at approximately $20 \mathrm{~mm}$ of punch displacement, extends for a wider range of the punch displacement when considering the full blank geometry.

Although the selected steels present a quite different mechanical behaviour (see Fig. 6), the punch force is only slightly higher in the high strength steel, as shown in Fig. 11. However, the friction coefficient between the dual phase steel DP600 and the forming tools is globally 


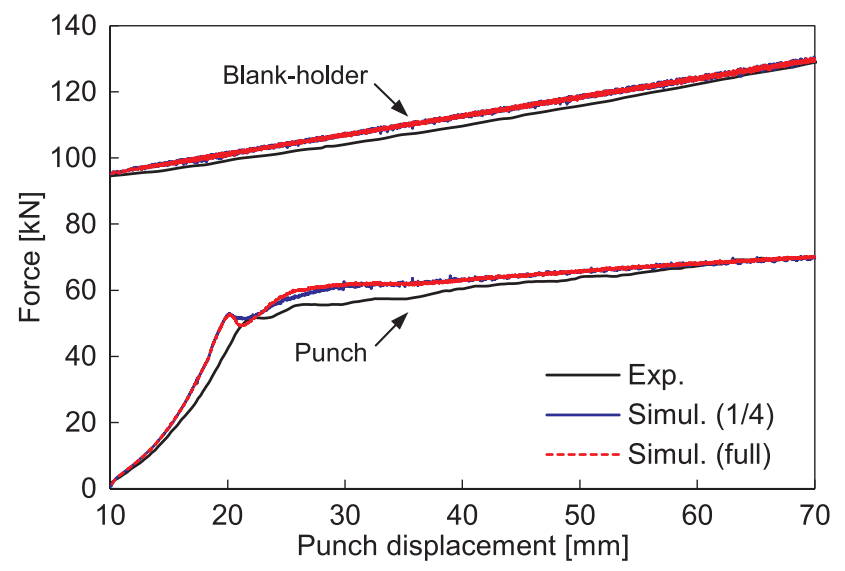

(a)

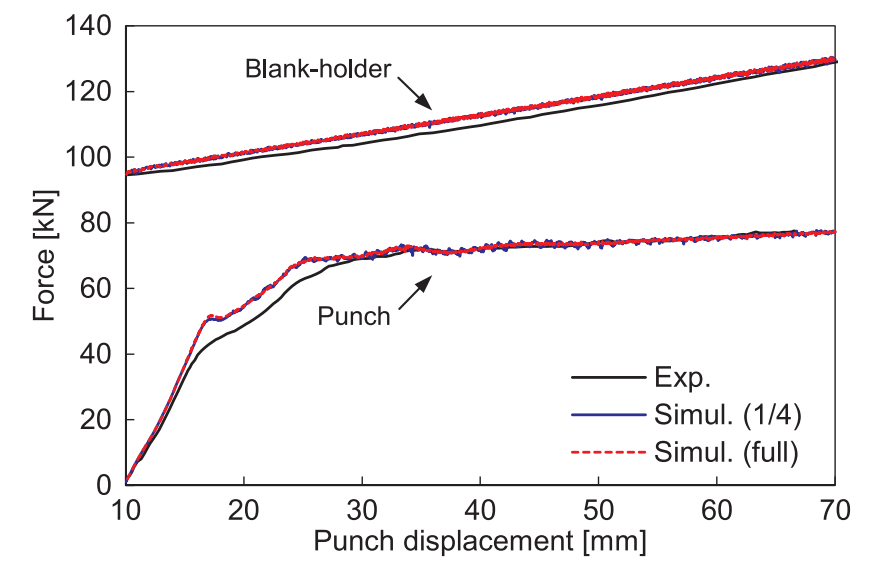

(b)

Fig. 11. Comparison between experimental and numerical punch/blank-holder force evolution in the forming of the rail considering the blank material: (a) DC06; (b) DP600.

lower than the one obtained for the DC06, as highlighted in Fig. 8. Besides, the local friction coefficient depends on the normal contact pressure through the relationship expressed by Eq. (4). The distribution of the contact pressure in both sides of the flange, at the end of the forming stage, is presented in Fig. 12 for both sheet steels. This figure presents only the flange area to highlight that the pressure imposed by the blank-holder is non-uniform. The maximum value of the contact pressure is substantially higher in the dual phase steel DP600, because its yield stress is considerably higher than the one of the mild steel DC06. Nevertheless, since the total applied blank-holder force is identical for both materials (Fig. 11), the flange area with effective contact pressure is smaller, as shown in Fig. 12. According to the relationship shown in Fig. 8, the distribution of the friction coefficient in both sides of the flange, at the end of the forming stage, is presented in Fig. 13 for both sheet steels. Most of the flange presents the higher value of friction coefficient since the contact pressure is very low or zero. On the other hand, the lower values of friction coefficient are located in the zones with high contact pressure.

\subsection{Section profiles}

The predicted geometry of the rail, after springback, considering the blank material DC06 and DP600 is presented in Fig. 14 and Fig. 15, respectively. For both materials in this study, the finite element simulation of the entire blank provides an unsymmetrical wrinkle geometry. In fact, this is in accordance with the experimental observation, as shown by the comparison between Fig. 14 (b) and Fig. 3(a) for the mild steel and by comparing Fig. 15 (b) with Fig. 3(b) for the dual phase steel. The uncertainties in the variables involved in the experi- mental tests cannot be avoided because it is their natural characteristic. Thus, the numerical models with full controlled process and deterministic results cannot reproduce accurately the experimental results, which are always prone to imperfections [45]. Since the wrinkling phenomenon arise from an instability (compressive stress), the slight rotation of the blank allows to improve the numerical prediction of the wrinkles geometry.

The final geometry for each rail component is evaluated using the four section profiles previously defined in Fig. 4(b), which allows the simultaneous evaluation of the springback and the wrinkle shape at the top surface. The comparison between experimental and numerical section profile $A(x=15 \mathrm{~mm})$ is presented in Fig. 16, for each material (DC06 and DP600). Regarding the numerical simulation, both finite element models ( $1 / 4$ and full blank) provide identical results. Since the yield stress of the dual phase steel DP600 is considerably higher than the one of the mild steel DC06 (see Fig. 6), the springback is larger for the dual phase steel rail. Considering the mild steel DC06, the numerical section profile is in good agreement with the experimental one, as shown in Fig. 16 (a).

In this study, the springback of the rail is evaluated at the section profile A using the "NXT Defect Evaluator"1 software package. The comparison between experimental and numerical (full model) distribution of the turning angle, after springback, is presented in Fig. 17 for each material (DC06 and DP600). The turning angle is calculated by measuring the angle between two consecutive nodes of the section profile and its horizontal alignment, i.e. the local rotation of the blank sheet [46]. The springback can be defined as the difference between the turning angle of the predicted geometry after unloading and the turning angle of the CAD geometry. Globally, the springback is significantly larger for the high strength steel rail (DP600), highlighting the influence of material yield stress on its magnitude [47]. For both materials (DC06 and DP600), the flange springback angle (section length higher than $90 \mathrm{~mm}$ ) is slightly overestimated by the numerical model, as shown in Fig. 17. Nevertheless, this angle is strongly associated with the turning angle of the vertical wall (section length ranging between $35 \mathrm{~mm}$ and $80 \mathrm{~mm}$ ). In fact, the flange springback angle can be understood as the integration of the turning angles along the aforesaid section [48]. Therefore, the value of the flange angle is only slightly overestimated by the numerical model because the turning angle of the vertical wall is underestimated, particularly for the dual phase DP600 (see Fig. 17). This difference can be related with the better prediction of the Bauschinger effect for the DC06 (see Fig. 6). On the other hand, the adoption of a constant value for the elastic modulus in the material model can affect the springback accuracy. Indeed, Ghaei [49] shows that the springback prediction of a U-rail (DP600 steel) is significantly improved considering the reduction of elastic modulus as a function of the effective plastic strain.

The comparison between the experimental and numerical section profile $B(x=95 \mathrm{~mm})$ is presented in Fig. 18, for each material (DC06 and DP600). The wrinkle arising on the top surface of the rail is highlighted in this profile, presenting distinct geometries according to the material of the blank. Considering the mild steel DC06, the numerical profile is in good agreement with the experimental one, excluding the top surface of the rail, where the two numerical models predict distinct geometries, as shown in Fig. 18 (a). In fact, the predicted wrinkle is symmetric using $1 / 4$ of the blank (see Fig. 14 (a)), while the adoption of the full blank geometry leads to an unsymmetrical wrinkle (see Fig. 14 (b)). Therefore, the full model of the blank provides a wrinkle geometry in better agreement with the experimental measurement, as shown in Fig. 18 (a). Regarding the dual phase steel DP600, the predicted profile of the wrinkle evaluated in this section is analogous in both finite element models, which is in good agreement with the experimental one (see Fig. 18 (b)). Indeed, the

\footnotetext{
${ }^{1}$ M \& M Research, Inc. http://www.m-research.co.jp/
} 


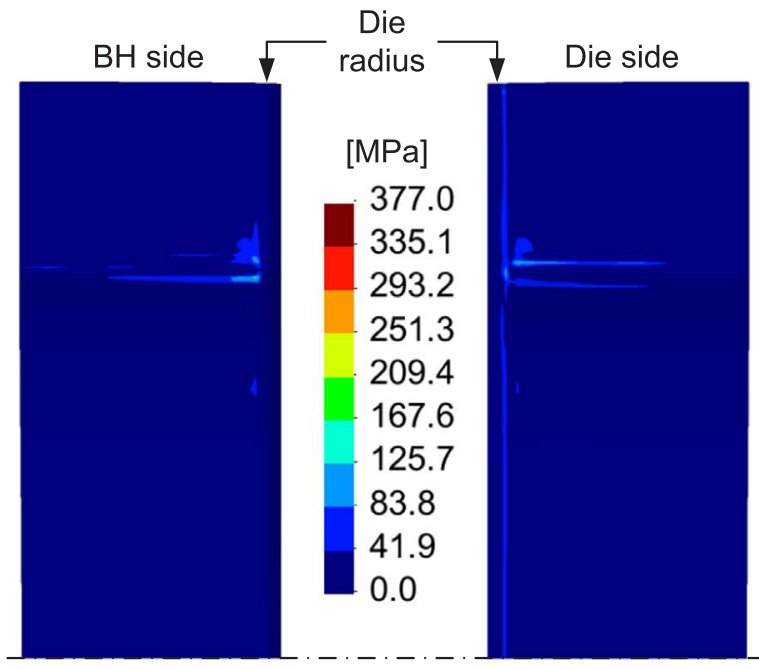

Symmetry plane

(a)

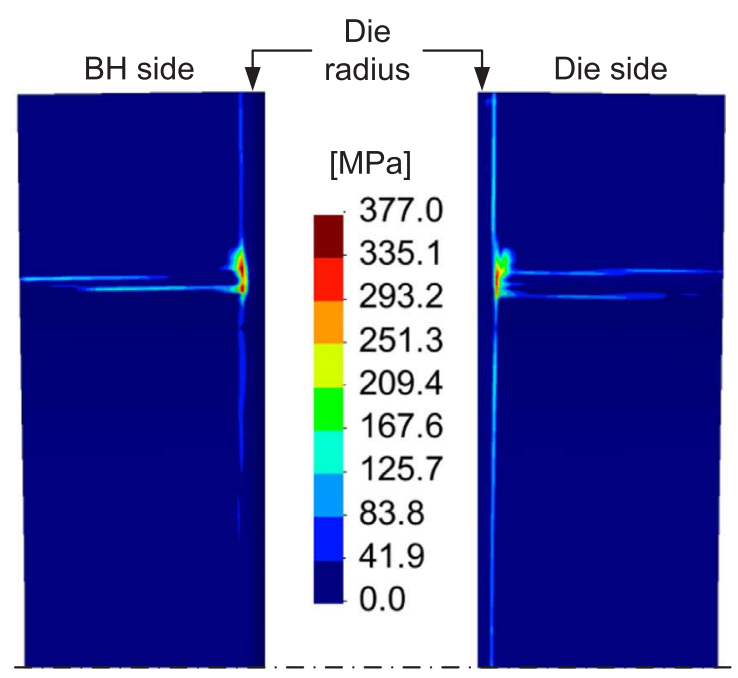

Symmetry plane

(b)

Fig. 12. Contact pressure distribution in both sides of the flange after forming: (a) DC06; (b) DP600.

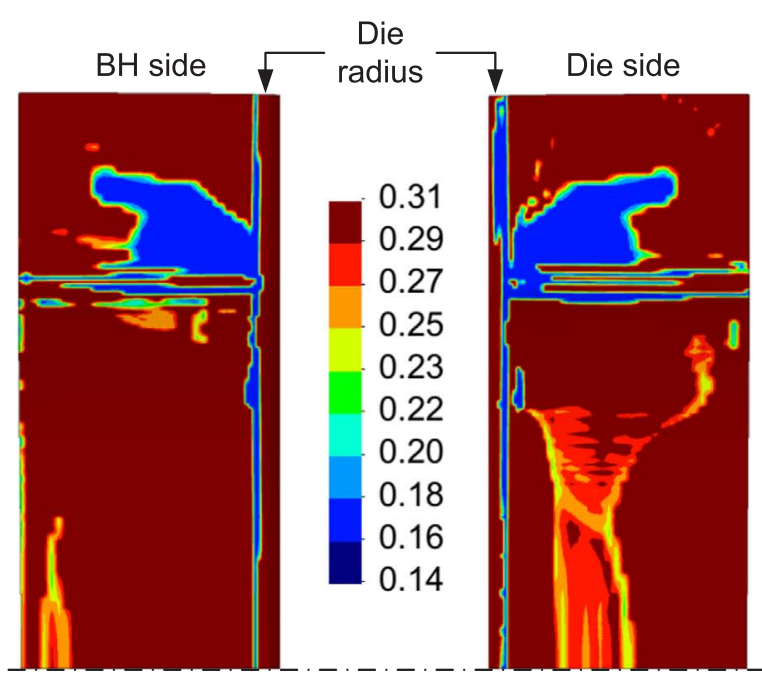

Symmetry plane

(a)

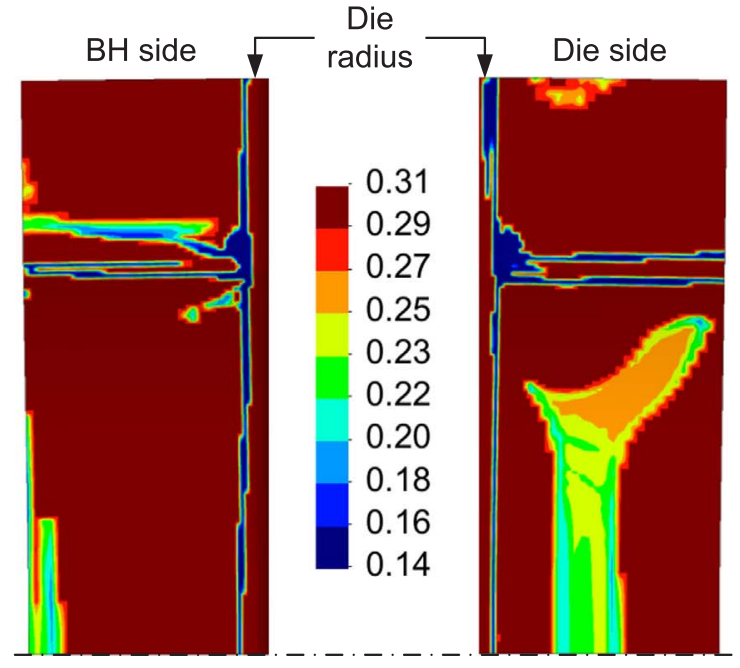

Symmetry plane

(b)

Fig. 13. Friction coefficient distribution in both sides of the flange after forming: (a) DC06; (b) DP600.

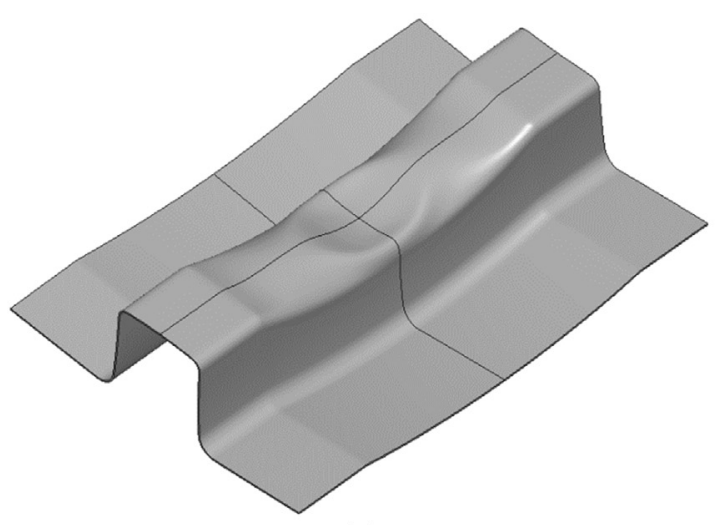

(a)

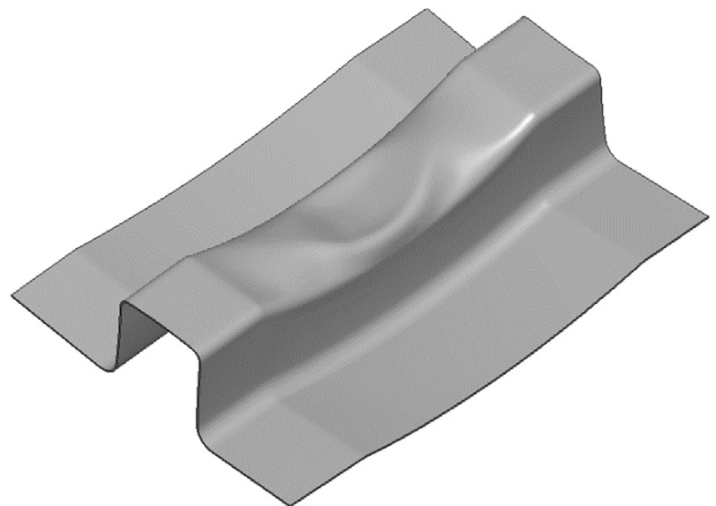

(b)

Fig. 14. Final geometry of the rail (DC06) predicted after springback: (a) $1 / 4$ of blank; (b) full blank (initially slightly rotated). 


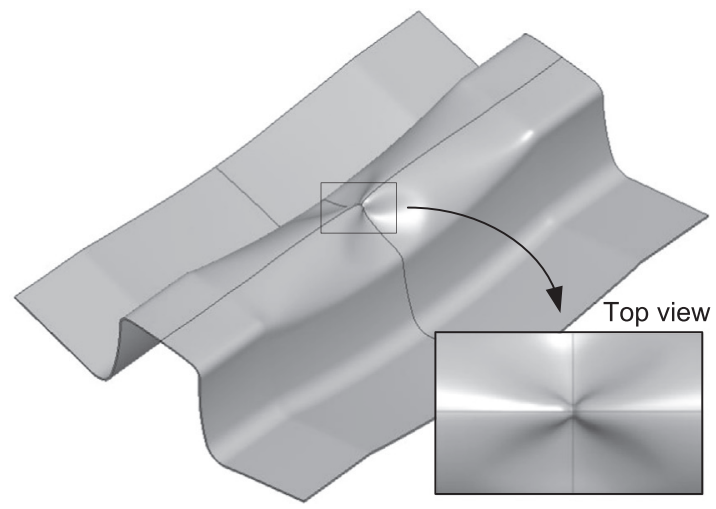

(a)

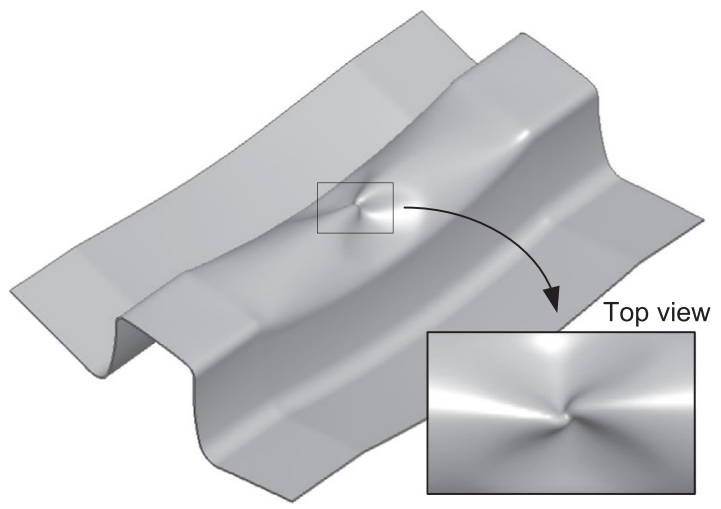

(b)

Fig. 15. Final geometry of the rail (DP600) predicted after springback, including a detailed view of the wrinkling area: (a) $1 / 4$ of blank; (b) full blank (initially slightly rotated).

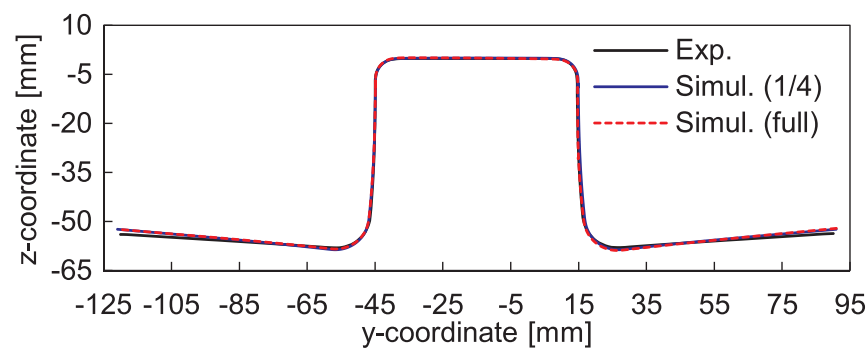

(a)

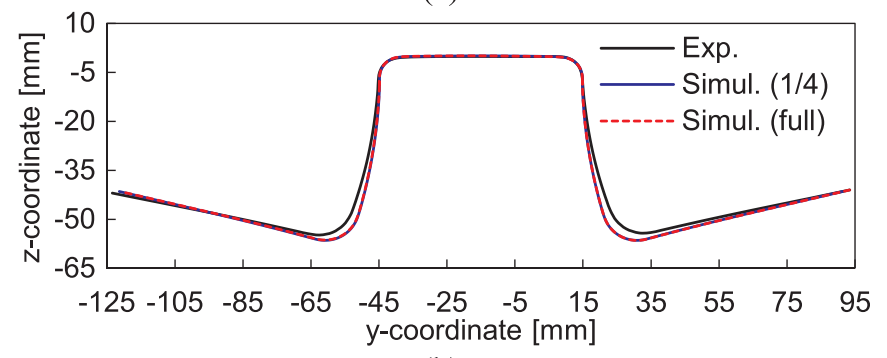

(b)

Fig. 16. Comparison between experimental and numerical section profile $A(x=15 \mathrm{~mm})$ considering the blank material: (a) DC06; (b) DP600.

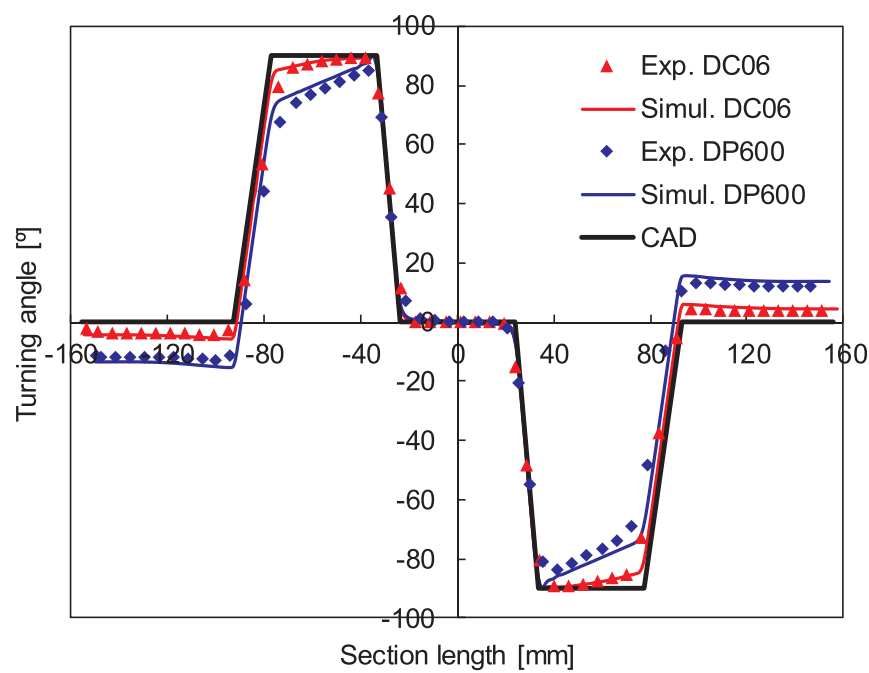

Fig. 17. Comparison between experimental and numerical distribution of the turning angle along the section profile A $(x=15 \mathrm{~mm})$ for DC06 and DP600 steels. The symmetry plane defines the zero coordinate for the section length.

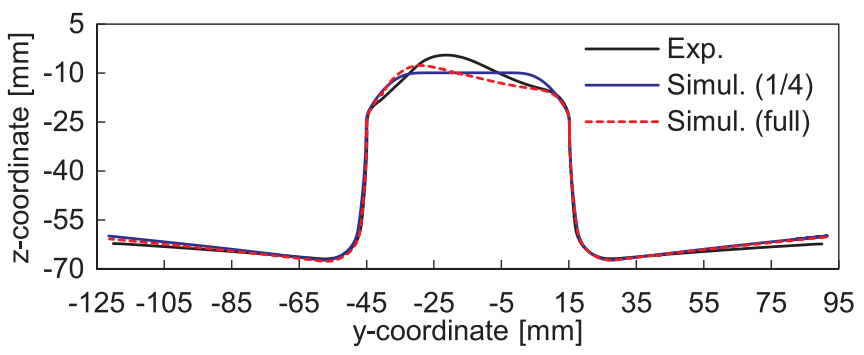

(a)

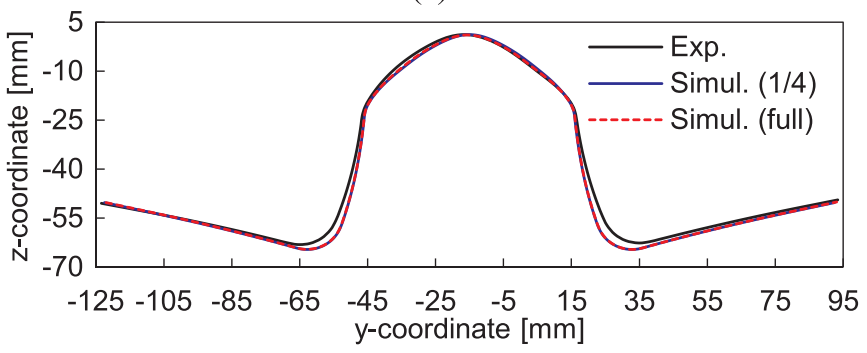

(b)

Fig. 18. Comparison between experimental and numerical section profile $B(x=95 \mathrm{~mm})$ considering the blank material: (a) DC06; (b) DP600.

wrinkle profile is almost symmetric in this section. For both sections analysed ( $x=15 \mathrm{~mm}$ in Fig. 16 and $x=95 \mathrm{~mm}$ in Fig. 18), the geometry of the flange is identical, indicating absence of twisting in the rail [50].

The comparison between the experimental and numerical section profile L1 $(\mathrm{y}=0 \mathrm{~mm})$ is presented in Fig. 19, for each material (DC06 and DP600). The shape of the wrinkle on the top surface of the rail presents distinct geometries according to the material of the blank. Due to the lower strength of the mild steel, the gap located in the top surface of the punch (see Fig. 10) is more easily reproduced in the geometry of the rail. Globally, the numerical predictions are in good agreement with the experimental measurements. Nevertheless, the predicted shape of the wrinkle is influenced by the boundary conditions used in the numerical model, mainly for the mild steel DC06 (Fig. 19 (a)). Indeed, considering the full blank geometry, the numerical results are in better agreement with the experimental ones, as shown in Fig. 19.

The comparison between the experimental and numerical section profile L2 $(\mathrm{y}=-30 \mathrm{~mm})$ is presented in Fig. 20, for each material. The numerical predictions are in good agreement with the experimental measurements, mainly considering the full blank geometry in the numerical model applied to the mild steel DC06 (see Fig. 20 (a)). For both materials, the numerical results of the section profiles L1 and L2 are approximately symmetrical to the plane $x=125 \mathrm{~mm}$, as shown in Fig. 19 and Fig. 20. However, the shape of the wrinkle arising for the dual phase steel is anti-symmetric (see Fig. 3(b) for experimental and 


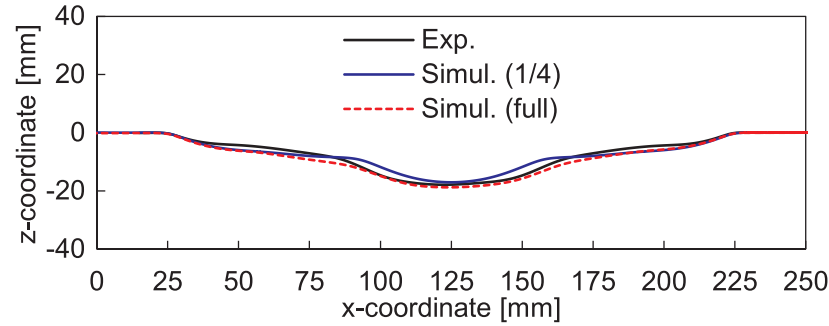

(a)

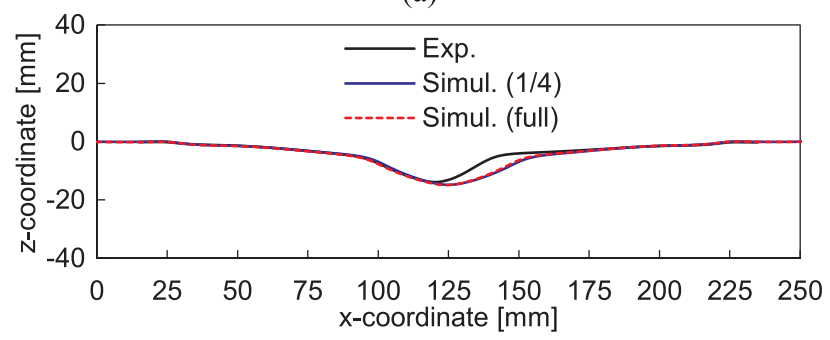

(b)

Fig. 19. Comparison between experimental and numerical section profile L1 ( $\mathrm{y}=0 \mathrm{~mm})$ considering the blank material: (a) DC06; (b) DP600.

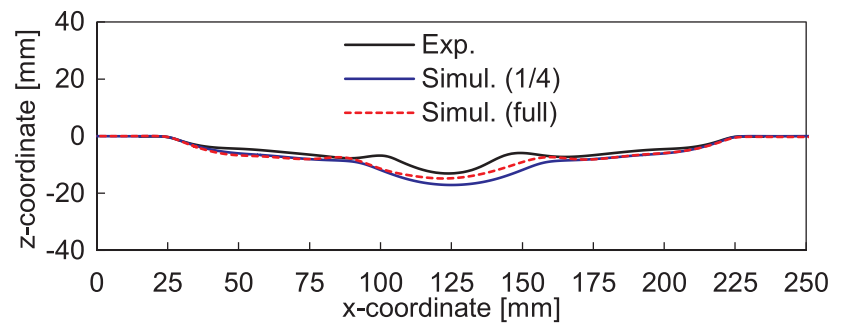

(a)

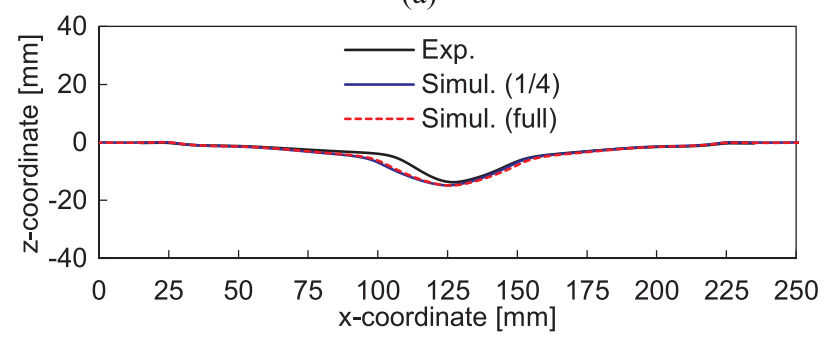

(b)

Fig. 20. Comparison between experimental and numerical section profile L2 $(y=-30 \mathrm{~mm}$ ) considering the blank material: (a) DC06; (b) DP600.

Fig. 15 (b) for numerical). This behaviour can be observed by comparing Fig. 19 (b) and Fig. 20 (b).

\subsection{Computational performance}

The computational performance for both finite element models is presented in Table 4. Despite the substantial improvement in the accuracy of the wrinkling prediction, the adoption of the full blank geometry leads to a significant increase on the computational cost. In

Table 4

Computational performance for full and 1/4 finite element models.

\begin{tabular}{|c|c|c|c|c|}
\hline & \multicolumn{2}{|l|}{ DC06 } & \multicolumn{2}{|l|}{ DP600 } \\
\hline & $1 / 4$ model & Full model & $1 / 4$ model & Full model \\
\hline $\mathrm{N}^{\circ}$ increments & 1823 & 4839 & 776 & 1544 \\
\hline Average $\mathrm{n}^{\circ}$ iterations & 9.4 & 8.4 & 10.1 & 9.1 \\
\hline Computational time $[\mathrm{h}]$ & 30.3 & 384.7 & 10.0 & 105.7 \\
\hline
\end{tabular}

fact, the computational time for the full blank numerical simulations is at least 10 times higher than for the $1 / 4$ of the blank models. This is a consequence of the higher number of finite elements required for the blank discretization (4 times more). The same behaviour is observed for the number of increments, which increases about 2 times, due to the numerical algorithm for controlling the blank-holder force independently in each flange [27]. Regarding the number of iterations per increment, the average value is slightly lower in the full blank model, because the number of increments is considerably higher, as shown in Table 4.

Despite the effect of the finite element model adopted, the computational cost of the numerical simulations is significantly influenced by the material defined for the blank, as shown in Table 4. In fact, the computational time is approximately 3 times higher considering the mild steel DC06 in comparison with the dual phase steel DP600. This difference in the computational performance arises from the large difference in the mechanical strength of these two materials, producing a distinct behaviour in terms of wrinkling (compare Fig. 14 and Fig. 15) and springback (see Fig. 17). Since the applied blank-holder force is identical for both materials (Fig. 11), the number of nodes in contact with the blank-holder/die is higher when considering the mild steel DC06 (see Fig. 12). Thus, the algorithm used to control the blank-holder force [27] requires more iterations in each increment to achieve the target force.

\section{Conclusions}

This study presents the experimental and numerical analysis of a rail component, which is prone to 2D springback and wrinkling defects. Two different materials are used for the blank, namely the mild steel DC06 and the dual phase steel DP600, which exhibit distinct values of both yield strength and tensile strength. The frictional (lubricated) behaviour between the blank and the forming tools is experimentally evaluated through the flat-die test, allowing the definition of the friction coefficient evolution in function of the normal contact pressure. Accordingly, an advanced friction model is adopted in the finite element model, where the forming tools are assumed rigid and the sheet exhibits an elastoplastic behaviour (isotropic elastic and anisotropic plastic with kinematic hardening).

In order to assess the influence of the applied boundary conditions on the wrinkling prediction, two different finite element models are presented and compared in this work. The first one takes into account the symmetry conditions of the forming process, allowing to simulate only $1 / 4$ of the blank geometry. On the other hand, the second model considers the full blank geometry, which has a minor slight rotation to the standard position. The magnitude of the springback is significantly influenced by the strength of the blank material. Indeed, the flange springback angle is about 3 times higher in the dual phase steel than in the mild steel. For both materials, the numerical results are in good agreement with the experimental measurements. Regarding the punch force evolution, it is slightly overestimated by the numerical simulation, particularly in the mild steel. Due to the large difference in the mechanical strength of the selected materials, the shape of the wrinkle on the top surface of the rail is dependent on material. Although both finite element models provide identical results for the springback and forming forces, the shape of the wrinkle depends on the adopted numerical model. In fact, the numerical results are in better agreement with the experimental ones when the full blank geometry is considered (wrinkle tend to be unsymmetrical). Nevertheless, the computational cost of the numerical simulation considering the full blank is at least 10 times higher than using $1 / 4$ of the blank.

\section{Acknowledgements}

The authors gratefully acknowledge the financial support of the Portuguese Foundation for Science and Technology (FCT) under the 
projects with reference P2020-PTDC/EMS-TEC/0702/2014 (POCI-010145-FEDER-016779) and P2020-PTDC/EMS-TEC/6400/2014 (POCI01-0145-FEDER-016876) by UE/FEDER through the program COMPETE 2020. The first author is also grateful to the FCT for the Postdoctoral grant SFRH/BPD/101334/2014.

\section{References}

[1] Jeswiet J, Geiger M, Engel U, Kleiner M, Schikorra M, Duflou J. , et al. Metal forming progress since 2000. CIRP J Manuf Sci Technol 2008;1:2-17. http:// dx.doi.org/10.1016/j.cirpj.2008.06.005.

[2] Banu M, Takamura M, Hama T, Naidim O, Teodosiu C, Makinouchi A. Simulation of springback and wrinkling in stamping of a dual phase steel rail-shaped part. J Mater Process Technol 2006;173:178-84. http://dx.doi.org/10.1016/j.jmatprotec.2005.11.023.

[3] Wagoner RH, Lim H, Lee M-G. Advanced issues in springback. Int J Plast 2013;45:3-20. http://dx.doi.org/10.1016/j.ijplas.2012.08.006.

[4] Meinders T, Burchitz IA, Bonte MHA, Lingbeek RA. Numerical product design: springback prediction, compensation and optimization. Int $\mathrm{J}$ Mach Tools Manuf 2008;48:499-514. http://dx.doi.org/10.1016/j.ijmachtools.2007.08.006.

[5] Karafillis AP, Boyce MC. Tooling and binder design for sheet metal forming processes compensating springback error. Int J Mach Tools Manuf 1996;36:503-26. http://dx.doi.org/10.1016/0890-6955(95)00023-2.

[6] Wang Z, Hu Q, Yan J, Chen J. Springback prediction and compensation for the third generation of UHSS stamping based on a new kinematic hardening model and inertia relief approach. Int J Adv Manuf Technol 2016:1-11. http://dx.doi.org/ 10.1007/s00170-016-9439-x.

[7] Komgrit L, Hamasaki H, Hino R, Yoshida F. Elimination of springback of highstrength steel sheet by using additional bending with counter punch. $\mathrm{J}$ Mater Process Technol 2016;229:199-206. http://dx.doi.org/10.1016/j.jmatprotec.2015.08.029.

[8] Shafaat MA, Abbasi M, Ketabchi M. Investigation into wall wrinkling in deep drawing process of conical cups. J Mater Process Technol 2011;211:1783-95. http://dx.doi.org/10.1016/j.jmatprotec.2011.05.026.

[9] Wang X, Cao J. On the prediction of side-wall wrinkling in sheet metal forming processes. Int J Mech Sci 2000;42:2369-94. http://dx.doi.org/10.1016/S00207403(99)00078-8.

[10] Ahmetoglu M, Broek TR, Kinzel G, Altan T. Control of blank holder force to eliminate wrinkling and fracture in deep-drawing rectangular parts. CIRP Ann Manuf Technol 1995;44:247-50. http://dx.doi.org/10.1016/S0007-8506(07) 62318-X.

[11] Tekkaya AE, Martins PAF. Accuracy, reliability and validity of finite element analysis in metal forming: a user's perspective. Eng Comput 2009;26:1026-55. http://dx.doi.org/10.1108/02644400910996880.

[12] Liu N, Yang H, Li H, Yan S. Plastic wrinkling prediction in thin-walled part forming process: a review. Chin J Aeronaut 2016;29:1-14. http://dx.doi.org/10.1016/ j.cja.2015.09.004.

[13] Kim JB, Yang DY. Prediction of wrinkling initiation in sheet metal forming processes. Eng Comput 2003;20:6-39. http://dx.doi.org/10.1108/ 02644400310458810 .

[14] De Magalhães Correia JP, Ferron G. Wrinkling of anisotropic metal sheets under deep-drawing: analytical and numerical study. J Mater Process Technol 2004;155156:1604-10. http://dx.doi.org/10.1016/j.jmatprotec.2004.04.270.

[15] Kim J-B, Yang D-Y, Yoon J-W, Barlat F. The effect of plastic anisotropy on compressive instability in sheet metal forming. Int J Plast 2000;16:649-76. http:// dx.doi.org/10.1016/S0749-6419(99)00064-9.

[16] Neto DM, Oliveira MC, Dick RE, Barros PD, Alves JL, Menezes LF. Numerical and experimental analysis of wrinkling during the cup drawing of an AA5042 aluminium alloy. Int J Mater Form 2017;10:34-7. http://dx.doi.org/10.1007/ s12289-015-1265-4.

[17] Mori N. 3DS - digital die design system; 2005.

[18] Santos AD, Reis A, Duarte JF, Teixeira P, Rocha AB, Oliveira MC. , et al. A benchmark for validation of numerical results in sheet metal forming. J Mater Process Technol 2004;155-156:1980-5. http://dx.doi.org/10.1016/j.jmatprotec.2004.04.290.

[19] Garcia D, Orteu J, Penazzi L. A combined temporal tracking and stereo-correlation technique for accurate measurement of 3D displacements: application to sheet metal forming. J Mater Process Technol 2002;125-126:736-42. http://dx.doi.org/ 10.1016/S0924-0136(02)00380-1.

[20] Xue X, Liao J, Vincze G, Sousa J, Barlat F, Gracio J. Modelling and sensitivity analysis of twist springback in deep drawing of dual-phase steel. Mater Des 2016;90:204-17. http://dx.doi.org/10.1016/j.matdes.2015.10.127.

[21] Li Y, Gu P. Free-form surface inspection techniques state of the art review. Comput Des 2004;36:1395-417. http://dx.doi.org/10.1016/j.cad.2004.02.009.

[22] Santos AD, Ferreira Duarte J, Reis A, Barata da Rocha A, Menezes L, Oliveira M. , et al. Towards standard benchmarks and reference data for validation and improvement of numerical simulation in sheet metal forming. J Mater Process Technol 2002;125-126:798-805. http://dx.doi.org/10.1016/S0924-0136(02) 00395-3.

[23] Eggertsen P-A, Mattiasson K. Experiences from experimental and numerical springback studies of a semi-industrial forming tool. Int J Mater Form 2011;5:341-59. http://dx.doi.org/10.1007/s12289-011-1052-9.

[24] Szakaly ED, Lenard JG. The effect of process and material parameters on the coefficient of friction in the flat-die test. J Mater Process Technol 2010;210:868-76. http://dx.doi.org/10.1016/j.jmatprotec.2010.01.019.

[25] Wouters P, Daniel D, Magny C. Selection and identification of friction models for the 3DS materials-identification of the frictional behaviour. Digital Die Design Systems (3DS) IMS 1999 000051; 2002

[26] Menezes LF, Teodosiu C. Three-dimensional numerical simulation of the deepdrawing process using solid finite elements. J Mater Process Technol 2000;97:100-6. http://dx.doi.org/10.1016/S0924-0136(99)00345-3.

[27] Oliveira MC, Alves JL, Menezes LF. Algorithms and strategies for treatment of large deformation frictional contact in the numerical simulation of deep drawing process. Arch Comput Methods Eng 2008;15:113-62. http://dx.doi.org/10.1007/s11831008-9018-X.

[28] Menezes LF, Neto DM, Oliveira MC, Alves JL. Improving computational performance through HPC techniques: case study using DD3IMP in-house code. AIP Conf Proc 2011;1353:1220-5. http://dx.doi.org/10.1063/1.3589683.

[29] Sun L, Wagoner RH. Complex unloading behavior: nature of the deformation and its consistent constitutive representation. Int J Plast 2011;27:1126-44. http:// dx.doi.org/10.1016/j.ijplas.2010.12.003.

[30] Chen Z, Bong HJ, Li D, Wagoner RH. The elastic-plastic transition of metals. Int J Plast 2016;83:178-201. http://dx.doi.org/10.1016/j.ijplas.2016.04.009.

[31] Frederick CO, Armstrong PJ. A mathematical representation of the multiaxial Bauschinger effect. Mater High Temp 2007;24:1-26. http://dx.doi.org/10.1179/ 096034007 X207589.

[32] Chen J, Xiao Y, Ding W, Zhu X. Describing the non-saturating cyclic hardening behavior with a newly developed kinematic hardening model and its application in springback prediction of DP sheet metals. J Mater Process Technol 2015;215:151-8. http://dx.doi.org/10.1016/j.jmatprotec.2014.08.014.

[33] Chongthairungruang B, Uthaisangsuk V, Suranuntchai S, Jirathearanat S. Springback prediction in sheet metal forming of high strength steels. Mater Des 2013;50:253-66. http://dx.doi.org/10.1016/j.matdes.2013.02.060.

[34] Sumikawa S, Ishiwatari A, Hiramoto J, Urabe T. Improvement of springback prediction accuracy using material model considering elastoplastic anisotropy and Bauschinger effect. J Mater Process Technol 2016;230:1-7. http://dx.doi.org/ 10.1016/j.jmatprotec.2015.11.004.

[35] Haddadi H, Bouvier S, Banu M, Maier C, Teodosiu C. Towards an accurate description of the anisotropic behaviour of sheet metals under large plastic deformations: modelling, numerical analysis and identification. Int $\mathrm{J}$ Plast 2006;22:2226-71. http://dx.doi.org/10.1016/j.ijplas.2006.03.010.

[36] Bouvier S, Teodosiu C, Maier C, Banu M, Tabacaru V. Selection and identification of elastoplastic models for the materials used in the benchmarks. Digital Die Design Systems (3DS) IMS 1999 000051; 2001

[37] Kim S, Lee J, Barlat F, Lee M-G. Formability prediction of advanced high strength steels using constitutive models characterized by uniaxial and biaxial experiments. J Mater Process Technol 2013;213:1929-42. http://dx.doi.org/10.1016/j.jmatprotec.2013.05.015.

[38] Chalal H, Racz S-G, Balan T. Springback of thick sheet AHSS subject to bending under tension. Int J Mech Sci 2012;59:104-14. http://dx.doi.org/10.1016/j.ijmecsci.2012.03.011.

[39] Kersting P, Gröbel D, Merklein M, Sieczkarek P, Wernicke S, Tekkaya AE. , et al. Experimental and numerical analysis of tribological effective surfaces for forming tools in sheet-bulk metal forming. Prod Eng 2016;10:37-50. http://dx.doi.org/ 10.1007/s11740-015-0651-6.

[40] Hughes TJR. Generalization of selective integration procedures to anisotropic and nonlinear media. Int J Numer Methods Eng 1980;15:1413-8. http://dx.doi.org/ 10.1002/nme.1620150914.

[41] Li KP, Carden WP, Wagoner RH. Simulation of springback. Int J Mech Sci 2002;44:103-22. http://dx.doi.org/10.1016/S0020-7403(01)00083-2.

[42] Neto DM, Oliveira MC, Menezes LF, Alves JL. Applying Nagata patches to smooth discretized surfaces used in 3D frictional contact problems. Comput Methods Appl Mech Eng 2014;271:296-320. http://dx.doi.org/10.1016/j.cma.2013.12.008.

[43] Neto DM, Oliveira MC, Menezes LF. Surface smoothing procedures in computational contact mechanics. Arch Comput Methods Eng 2017;24:37-87. http:// dx.doi.org/10.1007/s11831-015-9159-7.

[44] Neto DM, Oliveira MC, Menezes LF, Alves JL. Nagata patch interpolation using surface normal vectors evaluated from the IGES file. Finite Elem Anal Des 2013;72:35-46. http://dx.doi.org/10.1016/j.finel.2013.03.004.

[45] de Souza T, Rolfe B. Multivariate modelling of variability in sheet metal forming. J Mater Process Technol 2008;203:1-12. http://dx.doi.org/10.1016/j.jmatprotec.2007.09.075.

[46] Kase K, Makinouchi A, Nakagawa T, Suzuki H, Kimura F. Shape error evaluation method of free-form surfaces. Comput Des 1999;31:495-505. http://dx.doi.org/ 10.1016/S0010-4485(99)00046-9.

[47] Chen P, Koç M. Simulation of springback variation in forming of advanced high strength steels. J Mater Process Technol 2007;190:189-98. http://dx.doi.org/ 10.1016/j.jmatprotec.2007.02.046.

[48] Oliveira MC, Alves JL, Chaparro B, Menezes LF. Study on the influence of workhardening modeling in springback prediction. Int J Plast 2007;23:516-43. http:// dx.doi.org/10.1016/j.ijplas.2006.07.003.

[49] Ghaei A. Numerical simulation of springback using an extended return mapping algorithm considering strain dependency of elastic modulus. Int J Mech Sci 2012;65:38-47. http://dx.doi.org/10.1016/j.ijmecsci.2012.09.002.

[50] Pham CH, Thuillier S, Manach PY. Twisting analysis of ultra-thin metallic sheets. J Mater Process Technol 2014;214:844-55. http://dx.doi.org/10.1016/j.jmatprotec.2013.12.006. 